\title{
Transesterification of Waste Cooking Oil Catalysed by Crystalline Copper Doped Zinc Oxide Nanocatalyst
}

\author{
Sandhya $\mathrm{R}^{1}$ \\ Research Scholar, Departmentof \\ Mechanical Engineering, \\ PSG College of Technology, \\ Coimbatore 641004, India \\ Email: rssept19@gmail.com
}

\author{
Velavan $\mathrm{R}^{2}$ \\ Associate Professor, \\ Departmentof Mechanical \\ Engineering, \\ PSG College of Technology, \\ Coimbatore 641004, India \\ Email: vel@egy.psgtech.ac.in
}

\author{
Ravichandran $\mathrm{J}^{3}$ \\ Professor, \\ Department of Chemistry, \\ PSG College ofTechnology, \\ Coimbatore 641004, India \\ Email: drjravi@yahoo.co.in
}

\begin{abstract}
Biodiesel has its unique position in the field of renewable energy as alternate fuel to diesel due to fuel price, energy requirement and petroleum crisis. In this study, biodiesel was produced from Waste Cooking Oil (WCO) using Copper doped Zinc Oxide (CZO) nanocatalysts. The synthesized Copper doped Zinc Oxide nanocatalysts were characterized by X-Ray Diffraction (XRD) and High Resolution Transmission Electron Microscope (HRTEM). Design of experiment was framed using Taguchi method to limit the experiments and to find the optimum reaction conditions. The effect of process parameters such as oil-to-methanol ratio $(\mathrm{O} / \mathrm{M})$, catalyst type, catalyst concentration, temperature and time on the transesterification reactions using characterized Copper doped Zinc Oxide nanocatalyst were investigated. The 4\% (weight /weight) nanocatalyst concentration, 1:5 Oil to methanol molar ratio at $60^{\circ} \mathrm{C}$ temperature and 40 minutes of reaction time were found to be optimum, in which the maximum biodiesel yield of $98 \%(\mathrm{w} / \mathrm{w})$ was obtained. Hence it was determined that nanocatalysts exhibited good catalytic activities on biodiesel production from Waste Cooking Oil (WCO).
\end{abstract}

Keywords: Biodiesel, Waste Cooking Oil, Copper doped Zinc Oxide, Transesterification.

\section{Introduction}

Fossil fuels such as petroleum, coal and natural gas are the major sources of increased pollution level. Studieshave shown that biodiesel being less polluting, non-toxic and biodegradable; it can be used directly in most diesel engines without much engine modifications. Biodiesel is commonly produced by transesterification of lipids, animal fats, grease and waste cooking oils $[1,2,3,4,5,6,7,8,9,10,11,12,13]$.Catalyst plays an important role in transesterification reactions. Homogeneous catalysts result in the formation of soap which makes more complication in the reaction and also in the product separation. Heterogeneous catalysts has its own benefits such as ease of separation, easy recovery and can potentially be re-used. Finally, all these benefits leads to a reduced production cost [1, 2, 3, 6]. Due to the nanodimension and morphological structure, the nanocatalyst composites provides higher catalytic activity [14, 15]. This research work aims at conversion of WCO into biodiesel using the transesterification process with CZO nanocomposite as heterogeneous catalysts. Since nano particles have a large surface-to-volume ratio compared to bulk materials, they are attractive to use as catalysts for the transesterification reactions.

\section{Materials and methods}

\subsection{Materials}

Cupric sulphate, Zinc sulphate, Sodium carbonate were the chemicals used for synthesizing nanocatalyst. Methanol was used for transesterification reactions. All chemicals were of analytical grade purchased from Merck, India. Transesterification was carried out using Waste Cooking Oil, Copper doped Zinc Oxide nanocatalyst and methanol.

\subsection{Catalyst Synthesis}

Co-precipitation method was used for synthesizing CZO nanocatalyst. Solution 1was prepared by mixing $28.6 \%$ (w/v) of zinc sulfate with $1.52 \%(\mathrm{w} / \mathrm{v})$ of cupric sulfate in $100 \mathrm{ml}$ of distilled water. Solution 2 was prepared by mixing $5.28 \%$ of sodium carbonate in $100 \mathrm{ml}$ of distilled water. Then solution 1 was added in drops into solution 2under continuous stirring. The temperature was maintained as constant at $60^{\circ} \mathrm{C}$. The resultant bluish white precipitate was filtered, washed with distilled water and dried in hot air oven at $80^{\circ} \mathrm{C}$. The dried precipitate of $\mathrm{CZO}$ was calcinated at $500^{\circ} \mathrm{C}$ in a muffle furnace for 2 hour.

\subsection{Catalyst characterization}

Prepared catalysts were characterized by XRD and HRTEM.

Structural phase and crystalline size were identified by XRD analysis. The powder XRD patterns were recorded on a Shimadzu XRD 6000 , using CuKa radiation $\left(\lambda=1.54 A^{\circ}\right)$ over a $2 \theta$ range of $10^{\circ}-80^{\circ}$ with a scanning speed of $10^{\circ} / \mathrm{minute}$ at an accelerating voltage of $40 \mathrm{kV}$ and current of $30 \mathrm{~mA}$. 
HRTEM analysiswas done for direct imaging of the atomic structure of the sample. HRTEM images of different sizes such as $2 \mathrm{~nm}, 5 \mathrm{~nm}, 10 \mathrm{~nm}, 50 \mathrm{~nm}, 100 \mathrm{~nm}$ and $200 \mathrm{~nm}$ were taken on a JEM 2100, JEOL.

\subsection{Pre-treatment of Waste Cooking Oil}

WCOwas filtered to remove suspended solid materials. Then the oil was heated at $110^{\circ} \mathrm{C}$ to remove water content.

\subsection{Gas Chromatography (GC) Analysis of WCO}

Gas Chromatography (GC) coupled with Mass Spectroscopy (MS) (Thermo GC-Trace Ultra Ver: 5.0, Thermo MS DSQ II)was used for analysis of fatty acid content in WCO. Capillary non polar column DB 35- MS was used. Temperature program was carried out from 70 to $260^{\circ} \mathrm{C}$ at a heating rate of $6^{\circ} \mathrm{C} /$ minute using helium as carrier gas.

\subsection{Physical properties of WCO}

\subsubsection{Density}

Density of WCO was found out using hydrometer. Measured value of density was $902 \mathrm{~kg} / \mathrm{m}^{3}$.

\subsubsection{Kinematic Viscosity}

Viscosity of WCO was found out using redwood viscometer. Measured value of kinematic viscosity was $40 \mathrm{~mm}^{2} / \mathrm{s}$ at 40 ${ }^{\circ} \mathrm{C}$.

\subsubsection{Flash point}

Flash point is defined as the lowest temperature at which it forms vapour which produces combustible mixture with air. The flash and fire point temperatures depends upon the volatility of oil. Cleveland Open Cup apparatus was used for measuring flash and fire point. Measured value of flash point was $260^{\circ} \mathrm{C}$ and fire point $280^{\circ} \mathrm{C}$.

\subsubsection{Cloud Point and Pour point}

It is the temperature at which the oil becomes cloudy in appearance when it is cooled. At low temperatures when oil is cooled down, the impurities tend to separate out of the oil in the form of minute crystals that result in cloudiness. After the cloud point, the oil is cooled further, thus more and more of impurities will crystallize where the oil becomes gel. Measured value of cloud and pour point was $-2^{\circ} \mathrm{C}$ and $-8^{\circ} \mathrm{C}$.

\subsubsection{Acid Value}

Acid value is defined as the number of milligrams of potassium hydroxide required to neutralize the free acid present in one gram of oil sample. Measured acid value was $1.56 \mathrm{mg} \mathrm{KOH} / \mathrm{g}$.

\subsubsection{Saponification value}

Saponification number of oil is the number of milligrams of potassium hydroxide required to saponify one gram of oil. Measured saponification value by titration was $6.17 \mathrm{mg} \mathrm{KOH} / \mathrm{g}$.

\subsection{7. lodine value}

lodine value is the number of grams of iodine consumed by $100 \mathrm{~g}$ of oil. A known weight is allowed to react with an excess of standardized iodine solution and the iodine consumed by oil was estimated by blank titration with a standardized sodium thiosulphate solution. Measured value of iodine by titration was $5.92 \mathrm{I}_{2} \mathrm{~g} / 100 \mathrm{~g}$.

\subsection{Transesterification of WCO}

The transesterification is the basic process and it is accepted for large scale production of biodiesel [16]. The experiments were conducted in a round bottom flask equipped with heating, condensing and stirring facility as shown in Fig. 1. The process was carried out by mixing desired amount of catalyst, methanol and WCO. To prevent the methanol loss during a reaction, a water-cooled condenser was used. Transesterfication reaction was carried out for varied catalyst concentration $(2-8 \% \mathrm{w} / \mathrm{w})$, Oil to Methanol $(\mathrm{O} / \mathrm{M})$ ratio $(1: 2-1: 5 \mathrm{~mol})$, temperature $\left(40-70^{\circ} \mathrm{C}\right)$ and reaction time $(30-60$ minutes). After the desired duration the reaction mixture was allowed to settle and then transferred to a separating funnel. The biodiesel was allowed to separate from the mixture. Then, the unreacted methanol in the methyl esters were removed by heating the product to $110^{\circ} \mathrm{C}$ and maintained for $1 \mathrm{hr}$. This biodiesel was then collected and stored in an air-tight bottle at room temperature as shown in Fig. 2. Catalyst can be recovered, washed, calcined and reused. It is observed that minimum amount of catalyst is consumed in the reaction $[17,18]$. 


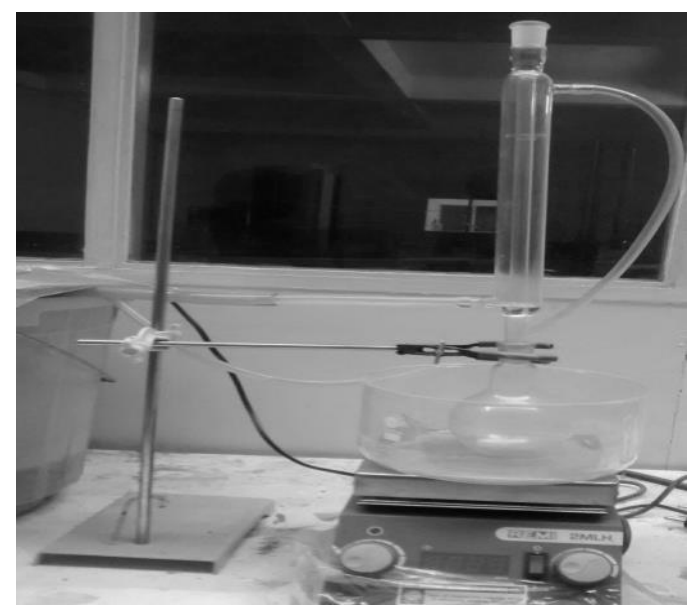

Fig. 1. Experimental set up

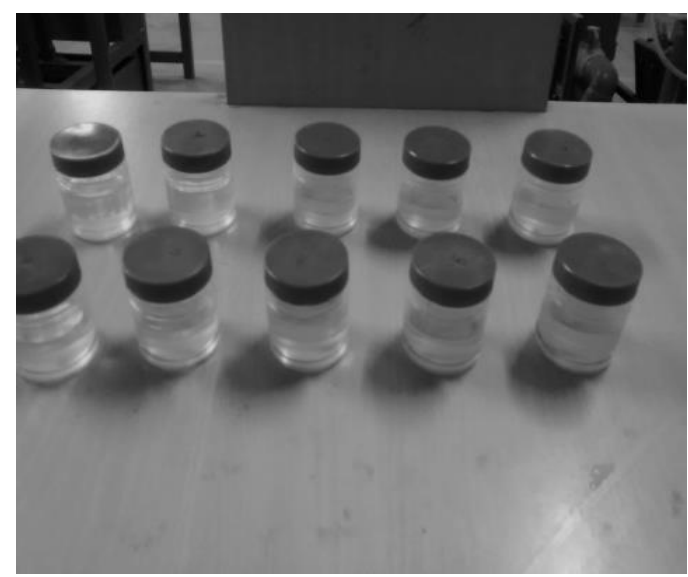

Fig. 2. Biodiesel

\subsection{Design of Experiments (DOE)}

Design of experiments (DOE) is an approach to study the relationship between factors affecting a process and the output of that process. This relationship is required to optimize the process inputs in order to obtain the maximum output. Here the effect of process parameters on the yield is investigated.

Taguchi method is used to reduce the number of experiments in case of large number of experimental situation. On the basis of Taguchi design, Orthogonal array was formed with 4 parameters at 4 levels as shown in table 1.

Table. Parameters and their levels in experimental design

\begin{tabular}{ccccc}
\hline Parameters & $\mathbf{5}$ & $\mathbf{2}$ & $\mathbf{3}$ & $\mathbf{4}$ \\
\hline $\begin{array}{c}\text { Catalyst amount } \\
(\% \mathrm{w} / \mathrm{w})\end{array}$ & 2 & 4 & 6 & 8 \\
$\begin{array}{c}\text { Oil to methanol } \\
\text { ratio (mol) }\end{array}$ & $1: 2$ & $1: 3$ & $1: 4$ & $1: 5$ \\
$\begin{array}{c}\text { Temperature }\left({ }^{\circ} \mathrm{C}\right) \\
\quad\end{array}$ & 40 & 50 & 60 & 70 \\
Time (minutes) & 30 & 40 & 50 & 60 \\
\hline
\end{tabular}


Signal to noise ratio was determined for the experiments in order to find the quality of production. There are three forms of signal to noise $(\mathrm{S} / \mathrm{N})$ ratio that are common interest for optimization of static problems.

Smaller-the-better expressed as $\eta=-10 \mathrm{Log}$ [mean of sum of squares of measured data]

$\eta=-10 \mathrm{Log}$ [mean of sum of squares of \{measured-ideal\}]

Larger-the-better expressed as $\eta=-10 \mathrm{Log}$ [mean of sum of squares of reciprocal of measured data]

Nominal-the-better expressed as $\eta=-10$ Log [square of mean/variance]

In order to maximize the percentage of yield, the optimum level for a factor is the level that gives the highest value of $\eta$ in the experimental design was chosen.

\section{Results and discussions}

\subsection{Catalyst Synthesis}

Various percentage of catalyst was synthesized such as $2 \%, 4 \%, 6 \%$ and $8 \%$. In each percentage of catalyst loading, 4 experiments have to be conducted based on DOE. Thus the required amount of catalyst $(\mathrm{g})$ for the process is calculated to be 4 times that of the each catalyst loading $(\mathrm{g})$. Total amount of catalyst required for conducting 16 experiments was shown in table 2.

Table 2. Amount of catalyst Synthesized

\begin{tabular}{ccccc}
\hline S.No. & Catalyst loading (\%) & Catalyst loading (g) & No. of experiments & $\begin{array}{c}\text { Required amount of } \\
\text { catalyst (g) }\end{array}$ \\
\hline 1 & 2 & 0.902 & 4 & 3.608 \\
2 & 4 & 1.804 & 4 & 7.216 \\
3 & 6 & 2.706 & 4 & 10.824 \\
4 & 8 & 3.608 & 4 & 14.432 \\
& & & & 36.08
\end{tabular}

\subsection{Characterization of CZO nanocatalyst by XRD}

XRD investigates crystallite size and structural phase. The most intense peak for the catalyst is at Bragg's angle of $36.6467^{\circ}$ and this was used to calculate the average CZO crystallite size (D) using Scherrer equation [15].

$$
D=\frac{k \lambda}{\beta \cos \theta}
$$

Where $k=$ shape factor $(0.9)$, FWHM $(\beta)=$ line broadening at half the maximum intensity in degrees, $\lambda=$ wavelength of $x$ rays, $2 \theta=$ Braggs diffraction angle. However, the results were used to calculate average crystallite size. Calculated average crystallite size was found to be $18.75 \mathrm{~nm}$.

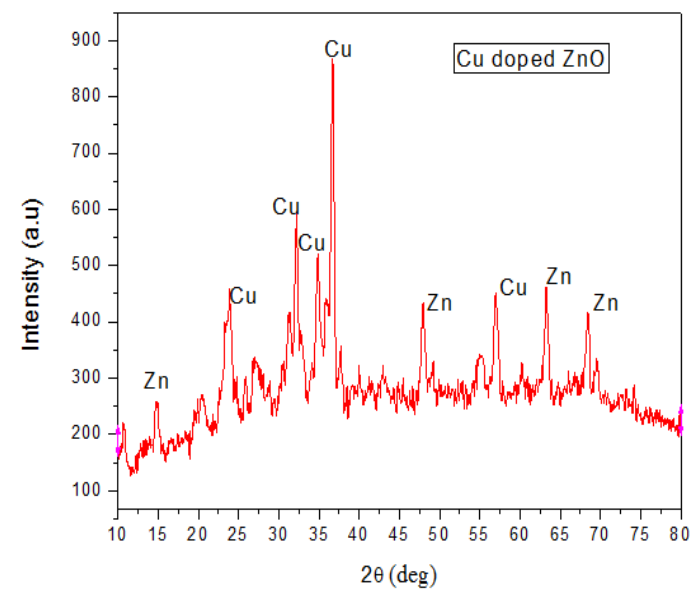

Fig. 3. XRD analysis of Cu doped Zinc oxide nanocatalyst 
Three strongest peaks at $2 \theta$ value of $36.6467^{\circ}, 32.1564^{\circ}$ and $34.8484^{\circ}$ confirms the presence of copper as shown in the Fig. 3. Indexed peaks with hkl planes were shown in Fig. 4.

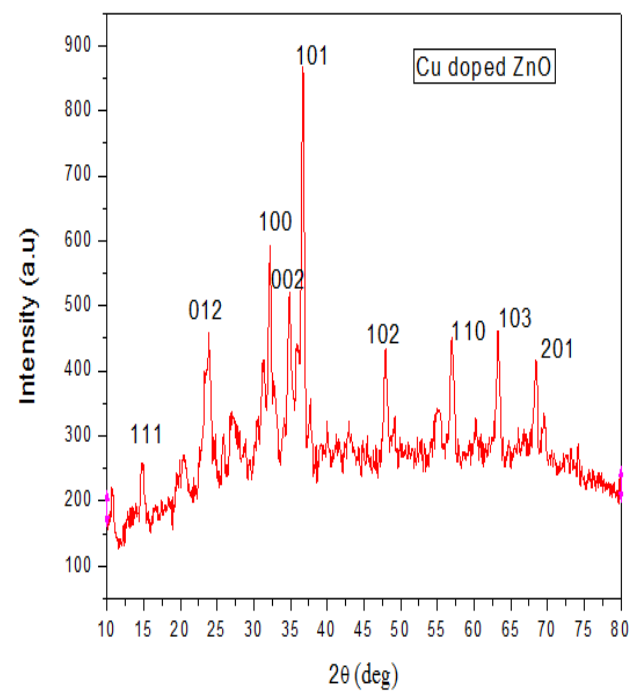

Fig. 4. Peaks indexed with hkl planes

XRD analysis reported that it is highly-symmetric, singly-crystalline. Its hexagonal lattice matched catalysts lattice structure.

\subsection{Characterization of CZO nanocatalyst by HRTEM Analysis}

Morphology and atomic structure of the sample were studied by HRTEM. From the HRTEM images, the copper particles were seen on the surface of zinc oxide which is clear from each level. The electrons in the energy levels were focused on the catalyst as shown in Fig. 5. HRTEM image of prepared CZO at $20 \mathrm{~nm}$ was shown in the Fig. 6.

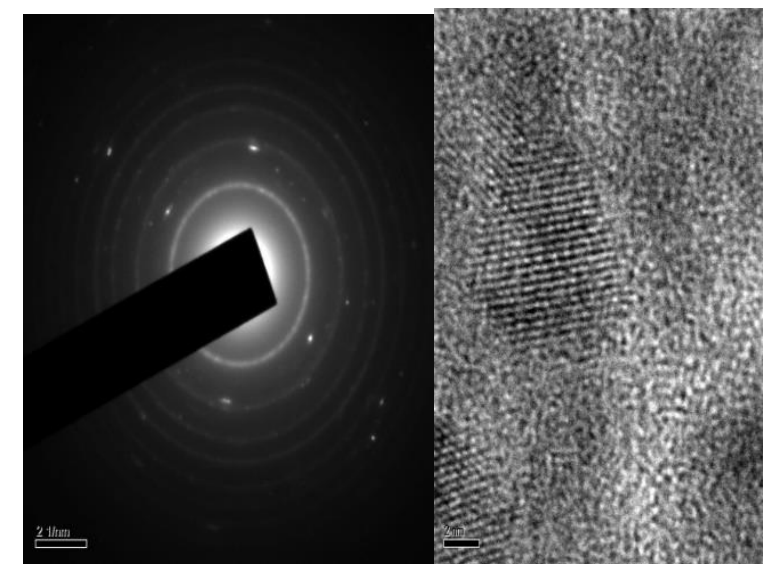

Fig. 5. HRTEM Images

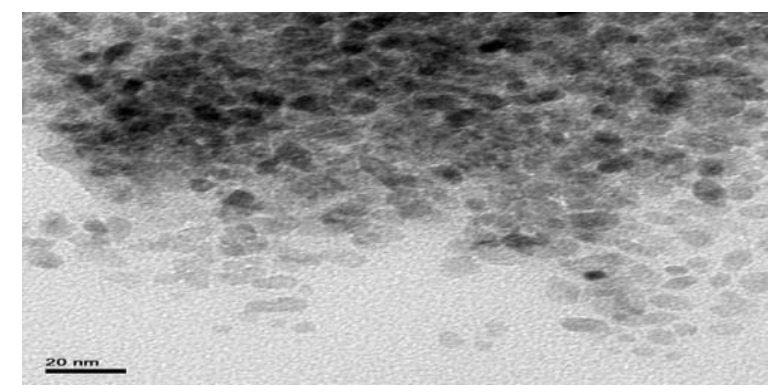

Fig. 6. Particle Size Distribution 


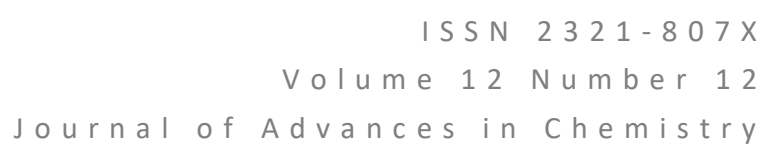

HRTEM images of different sizes such as $2 \mathrm{~nm}, 5 \mathrm{~nm}, 10 \mathrm{~nm}, 50 \mathrm{~nm}, 100 \mathrm{~nm}$ and $200 \mathrm{~nm}$ were taken. Nearly 25 HRTEM images of different sizes were taken and in that a region with clear fringes was chosen for making each fringe to a one-pixel width. So that it will be easier for analyzing the nanostructure of the catalyst. Increase in surface area of a particle boosts the catalytic activity of CZO. Lattice fringes appear as light and dark bands in the image caused by the diffraction of the incident electrons by the specimen. Crossed lattice fringes are formed by the intersection of two or more sets of lattice fringes. Crossed lattice fringes will be visible when the nanocrystal is oriented close to a zone axis.

\subsubsection{Energy Dispersive X-Ray (EDX) Analysis}

Energy Dispersive X-Ray Analysis was done. From the spectrum it is clear that it confirms the presence of copper and zinc. Composition of elements in the synthesised catalyst is given in the table 3 . Composition table shows that zinc occupies a major part. Each peak in the spectrum represents the presence of each element. Each peak is indexed by their chemical formula shown in Fig. 7 [19].

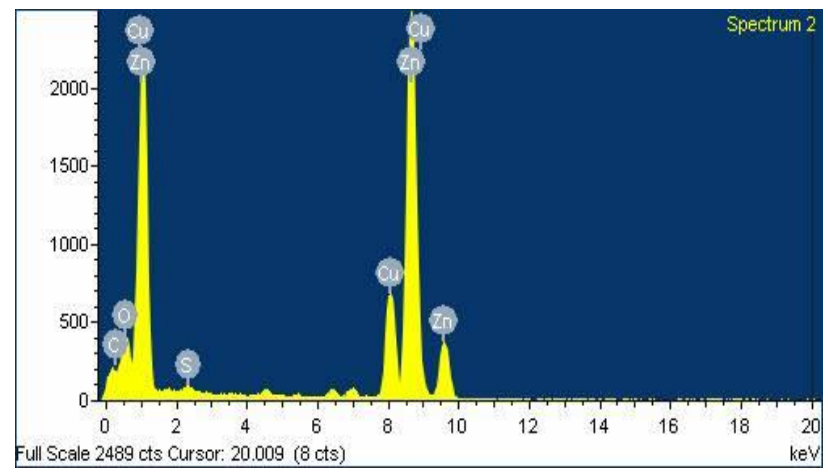

Fig. 7. Energy Dispersive X-Ray (EDX) Spectrum

\subsection{Gas Chromatography (GC) Analysis of WCO}

Composition of fatty acids in WCO were identified using GC-MS. Fatty acids in WCO were quantified by comparing their retention times and peak areas to those of standard fatty acids shown in table 3 [20,21].

TABLE 3. MajorComposition of fatty acids in WCO

\begin{tabular}{cc}
\hline Fatty acid methyl esters & Weight, \% \\
\hline Archidate & 2.05 \\
Lignocerate & 2.62 \\
Palmitate & 3.48 \\
Decanoate & 2.46 \\
Gamma & 16.42 \\
Docosahexane & 19.97 \\
Oleic Acid & 2.37 \\
\hline
\end{tabular}

\subsection{Comparison of Properties}

Properties comparison is one of the methods to determine the standard of biodiesel. Biodiesel property values can be checked by verifying it with the ASTM D6751 standard shown in table 4 [22, 23, 24, 25, 26]. 
TABLE 4.Properties of biodiesel compared to diesel fuel and ASTM D6751 biodiesel standard

\begin{tabular}{|c|c|c|c|c|}
\hline S.No. & Properties & Biodiesel & Diesel & ASTM D6751 \\
\hline 1. & Density $\left(\mathrm{kg} / \mathrm{m}^{3}\right)$ & 897 & 850 & $820-900$ \\
\hline 2. & Kinematic Viscosity $\left(\mathrm{mm}^{2} / \mathrm{s}\right.$ at $\left.40^{\circ} \mathrm{C}\right)$ & 4.7 & $3.0-8.0$ & $1.9-6.0$ \\
\hline 3. & Flash point and Fire point $\left({ }^{\circ} \mathrm{C}\right)$ & 157 & $>65$ & 130 minimum \\
\hline 4. & Cloud point and Pour point $\left({ }^{\circ} \mathrm{C}\right)$ & -5 and -7 & $\begin{array}{l}-15 \text { to }-35 \\
10 \text { to }-20\end{array}$ & - \\
\hline 5. & $\begin{array}{l}\text { Acid value } \\
(\mathrm{mg} \mathrm{KOH} / \mathrm{g})\end{array}$ & 0.42 & $<0.1$ & 0.5 maximum \\
\hline 6. & $\begin{array}{l}\text { Saponification value } \\
\qquad(\mathrm{mg} \mathrm{KOH} / \mathrm{g})\end{array}$ & 192 & - & - \\
\hline 7. & $\begin{array}{l}\text { lodine value } \\
\left(\mathrm{l}_{2} \mathrm{~g} / 100 \mathrm{~g}\right)\end{array}$ & 82 & - & - \\
\hline
\end{tabular}

Biodiesel produced seems to be matched with that of the ASTM D6751 biodiesel standard.

\subsection{DOE Experimental results}

Biodiesel conversion was investigated based on the Design Of Experiments i.e., range of the parameters such as $2-8 \%$ catalyst concentration, $1: 2$ to $1: 5$ oil to methanol ratio, $40-70^{\circ} \mathrm{C}$ reaction temperature and $30-60$ minutes reaction time. Biodiesel yield depends on the process operating conditions [27]. Orthogonal array is used to design experiments with four parameters at four levels, L-16 shown in table 5.

TABLE 5. Experimental results

\begin{tabular}{cccccl}
\hline \multicolumn{5}{c}{ S. } & \multicolumn{5}{c}{$\begin{array}{l}\text { Parameters } \\
\mathbf{N} \\
\mathbf{0}\end{array}$} & $\begin{array}{c}\text { Catalyst } \\
(\mathbf{w} / \mathbf{w}) \%\end{array}$ & $\begin{array}{c}\text { Tempe } \\
\text { rature( } \\
\left.{ }^{\circ} \mathbf{C}\right)\end{array}$ & $\begin{array}{l}\text { Time } \\
\text { (minut }\end{array}$ & $\begin{array}{l}\text { Oil to } \\
\text { Methano }\end{array}$ & $\begin{array}{l}\text { Yield } \\
\text { I ratio }\end{array}$ \\
\hline 1 & 2 & 40 & 30 & $1: 2$ & 90.6 \\
2 & 2 & 50 & 40 & $1: 3$ & 93.1 \\
3 & 2 & 60 & 50 & $1: 4$ & 75.8 \\
4 & 2 & 70 & 60 & $1: 5$ & 68.4 \\
5 & 4 & 50 & 50 & $1: 2$ & 77.4 \\
6 & 4 & 40 & 60 & $1: 3$ & 73.4 \\
7 & 4 & 70 & 30 & $1: 4$ & 78.5 \\
8 & 4 & 60 & 40 & $1: 5$ & 97.3 \\
9 & 6 & 60 & 60 & $1: 2$ & 68.6 \\
10 & 6 & 70 & 50 & $1: 3$ & 81.4 \\
11 & 6 & 40 & 40 & $1: 4$ & 92.1 \\
12 & 6 & 50 & 30 & $1: 5$ & 96.9 \\
\hline & & & & & \\
\hline
\end{tabular}




\begin{tabular}{llllll}
\hline 13 & 8 & 70 & 40 & $1: 2$ & 96.1 \\
14 & 8 & 60 & 30 & $1: 3$ & 97.7 \\
15 & 8 & 50 & 60 & $1: 4$ & 69.1 \\
16 & 8 & 40 & 50 & $1: 5$ & 75.3 \\
$\mathrm{C}$ & 8 & 60 & 30 & $1: 3$ & 98.0 \\
$\mathrm{~T}$ & & & & & \\
\hline
\end{tabular}

\section{CT- Confirmation test}

Confirmation test was done to validate the taguchi method. In this study, Minitab 17 software was used for automatic design to analyze the results and also to optimize the experimental conditions.

\subsubsection{Effect of catalyst concentration}

Nanocatalyst posses large surface area, which make them more suitable for the catalytic activity. The effects of the catalyst concentration on methyl ester yield were investigated by changing the weight ratio of the catalyst in the range of $2-8 \%$. When the catalyst concentration was increased from $2 \mathrm{wt} \%$ to $8 \mathrm{wt} \%$ the conversion reached $97.7 \%$. Thus transesterification reaction was strongly affected by catalyst concentration. The results show that they are in agreement with the literatures $[28,29,30]$.

\subsubsection{Effect of oil to methanol ratio}

Oil to methanol ratio is one of the important parameter which affects the transesterification. The effect of $O / M$ ratio on methyl ester yield was studied by varying oil to methanol ratio from $1: 2$ to $1: 5$ under the conditions of $2-8$ wt $\%$ catalyst, reaction temperature from $40-70^{\circ} \mathrm{C}$ and reaction time from 30-50 minute. The maximum biodiesel yield was obtained when $1: 3 \mathrm{O} / \mathrm{M}$ ratio, $8 \%$ catalyst, $60^{\circ} \mathrm{C}$ temperature and reaction time 30 minute was maintained. Thus sufficient amount of alcohol is required for high yield transesterification. The results show that they are in agreement with the literatures [29, $30,31]$.

\subsubsection{Effect of reaction temperature}

Based on the Design Of Experiments, the transesterification of WCO using CZO nanocatalyst was carried out at different temperature ranging from $40^{\circ} \mathrm{C}$ to $70^{\circ} \mathrm{C}$. The result indicates that the biodiesel conversion was high at lower temperature with only $2 \%$ catalyst. Increase in the temperature from $40^{\circ} \mathrm{C}$ to 50 and $60^{\circ} \mathrm{C}$ increases the yield with 4,6 and $8 \%$ catalyst loading. The maximum biodiesel yield was obtained at $60^{\circ} \mathrm{C}$. Then the conversion dropped on further increase in temperature of $70^{\circ} \mathrm{C}$. The optimal temperature for transesterification of WCO using CZO nanocatalyst was found to be 60 ${ }^{\circ} \mathrm{C}$. Thus transesterification occurs at various temperatures. The results show that they are in agreement with the literatures [29, 30, 31].

\subsubsection{Effect of reaction time}

Reaction time is another important criterion that will affect the yield of biodiesel. The effect of reaction time on conversion was studied from the Design Of Experiments framed and its corresponding yield obtained. Reaction was carried with variation in time from 30-60 minutes. Results show that there was an increase in conversion when the reaction time was in the range 30 to $40 \mathrm{~min}$

Thus level of conversion increases with reaction time. The results show that they are in agreement with the literatures [30, 31].

\section{Response of parameters with respect to Signal to noise ratio}

Basically during the process, noise factors will arise which is an uncontrollable one. In order to control the noise factors, the optimal control factor settings should be identified from the variation of response of parameters with respect to Signal to Noise ratio shown in Fig. 8.

Thus taguchi design is used to identify control factors which reduce the effect of noise factors. Based on table 6 , parameters are ranked and given in table 7. To have a minimum signal-to-noise ratio, the control factors have to shift from mean to the target. This is achieved by taguchi design. 


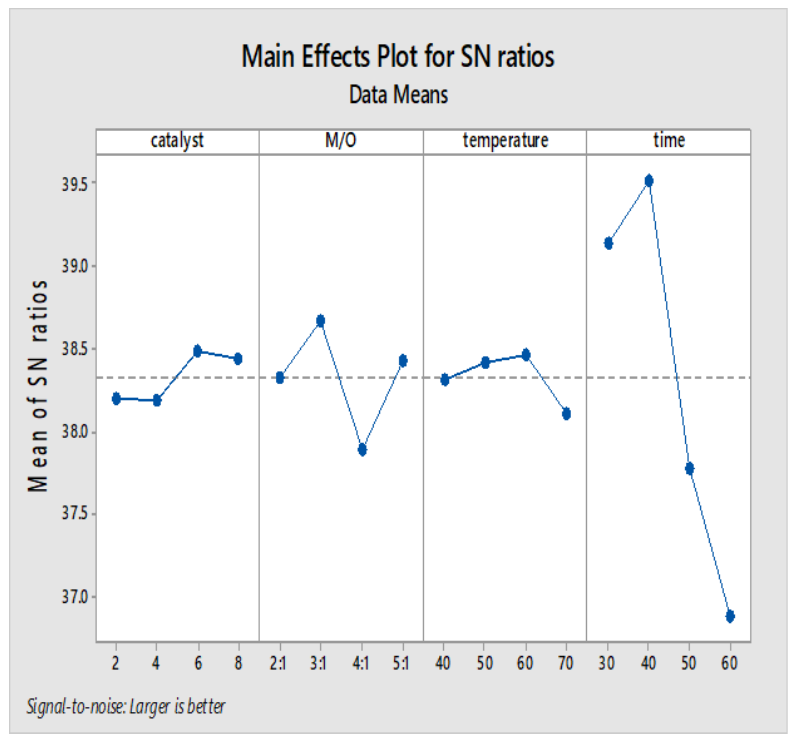

Fig. 8. Response graph of higher-the-better signal-to-noise ratios for fatty acid methyl aster (FAME) contents at different levels of factors

TABLE 6.Average Signal to Noise Ratios (S/N) Response Table for different parameter levels

\begin{tabular}{ccccc}
\hline Parameters & \multicolumn{3}{c}{ Levels } & $\mathbf{4}$ \\
\hline Catalyst loading $(\mathrm{w} / \mathrm{w}) \%$ & $\mathbf{1}$ & $\mathbf{2}$ & $\mathbf{3}$ & 38.44 \\
Methanol to oil ratio & 38.20 & 38.19 & 38.49 & 38.43 \\
Temperature in ${ }^{\circ} \mathrm{C}$ & 38.32 & 38.68 & 38.12 & 36.47 \\
Time in hrs & 38.32 & 38.42 & 37.78 & 39.83 \\
\hline
\end{tabular}

TABLE 7. Ranking of Parameters based on the response table of $\mathrm{S} / \mathrm{N}$ ratio and Means

\begin{tabular}{cc} 
Parameters & Ranking \\
\hline Catalyst loading $(\mathrm{w} / \mathrm{w}) \%$ & 4 \\
Oil to methanol ratio & 2 \\
Temperature in ${ }^{\circ} \mathrm{C}$ & 3 \\
Time in hrs & 1 \\
\hline
\end{tabular}

\section{Catalyst Life}

One of the most important benefit of using heterogeneous catalyst is its reusability. Experiments were carried out with the regenerated catalyst and the effect of reusability was studied. Catalyst once used for the reaction was collected, dried and utilized for the successive cycles. Stable catalytic activity was maintained for 5 successive cycles. Thus the catalyst life is 5 times. From the catalytic activity of CZO in the reaction, it is confirmed that it is an effective catalyst for production of biodiesel from WCO [14, 32]. 


\section{Conclusion}

CZO nanocatalyst prepared shows good catalytic activity for the transesterification of Waste Cooking Oil. The 4\% (w/w) nanocatalyst concentration, $1: 5 \mathrm{Oil}$ to Methanol ratio, $60^{\circ} \mathrm{C}$ temperature and 40 minute of reaction time were found to be optimum, in which the maximum biodiesel yield obtained was $97.7 \%(\mathrm{w} / \mathrm{w})$. Thus CZO shows great potential in the field of WCO processing.

\section{References}

[1] Sharma YC, Singh B, Korstad J (2011) Latest developments on application of heterogenous basic catalysts for an efficient and ecofriendly synthesis of biodiesel: a review. Fuel, vol. 90, pp. 1309-1324. doi:10.1016/j.fuel.2010.10.015

[2] Alhassan FH, Yunus R, Rashid U, Sirat K, Lee AI H.V, Taufiq-Yap YH (2013) Production of biodiesel from mixed waste vegetable oils using Ferric hydrogen sulphate as an effective reusable heterogeneous solid acid catalyst. Applied Catalysis A: General, vol.456, pp. 182-87. doi: 10.1016/j.apcata.2013.02.019

[3] Wan Omar WNR, Amin NAS (2011) Optimization of heterogeneous biodiesel production from waste cooking palm oil via response surface methodology. Biomass and bioenergy, vol.35, pp. 1329-1338.doi:1016/j.biombioe.2010.12.049

[4] Kumaran P, Mazlini N, Hussein I, Nazrain M, Khairul M (2011) Technical feasibility studies for Langkawi WCO (waste cooking oil) derived biodiesel. Energy, vol.36, pp. 1386-1393. doi: 10.1016/j.energy.2011.02.002

[5] Soriano Jr NU, Venditti R, Argyropoulos DS (2009) Biodiesel synthesis via homogeneous Lewis acid-catalyzed transesterification. Fuel, vol.88, pp. 560-565. doi: 10.1016/j.fuel.2008.10.013

[6] Kawentara WA, Budimanb A (2013) Synthesis of biodiesel from second-used cooking oil. Energy Procedia, vol.32, pp. 190 -199. doi:10.1016/j.egypro.2013.05.025

[7] Buczek B (2014) Diesel Fuel from Used Frying Oil. The Scientific World Journal,pp. 1-3. doi:10.1155/2014/683272

[8] Patle DS, Sharma S, Ahmad Z, Rangaiah G.P (2014) Multi-objective optimization of two alkali catalyzed processes for biodiesel from waste cooking oil. Energy Conversion and Management, vol.85, pp. 361-372. doi:10.1016/j.enconman.2014.05.034

[9] Komintarachat C, Chuepeng S (2010) Methanol-Based Transesterification Optimization of Waste Used Cooking Oil over Potassium Hydroxide Catalyst. American Journal of Applied Sciences, vol.7(8), pp. 1073-1078. doi: 10.3844/ajassp.2010.1073.1078

[10] Magín Lapuerta, Jose M. Herreros, Lisbeth L. Lyons, Reyes García-Contreras, Yolanda Briceno (2008) Effect of the alcohol type used in the production of waste cooking oil biodiesel on diesel performance and emissions. Fuel, vol. 87, pp. 3161-3169. doi:10.1016/j.fuel.2008.05.013

[11]Canakci M, Ozsezen AN (2005) Evaluating waste cooking oil as alternative diesel fuel. GU Journal of Science, vol.18(1), pp. 81- 91.

[12] Georgogianni KG, Kontominas MG, Tegou E, Avlonitis D, Vergis V(2007) Biodiesel production: reaction and process parameters of alkali-catalysed transesterification of waste frying-oils. Energy Fuels, vol.21, pp. 3023-3027.

[13] Shivakumar P. Srinivasa Pai , Shrinivasa Rao B.R (2011) Artificial Neural Network based prediction of performance and emission characteristics of a variable compression ratio $\mathrm{Cl}$ engine using $\mathrm{WCO}$ as a biodiesel at different injection timings. Applied Energy, vol.88, pp. 2344-2354. doi:10.1016/j.apenergy.2010.12.030

[14] Baskar G, Soumiya S (2016) Production of biodiesel from castor oil using iron (II) doped zinc oxide nanocatalyst. Renewable Energy xxx, pp.1-7. doi: 10.1016/j.renene.2016.02.068

[15] Ikenna C. Emeji, Ayo S. Afolabi (2015) Characterization and Kinetics of Biofuel Produced from Waste Cooking Oil.Proceedings of the World Congress on Engineering and Computer Science Vol II WCECS, October 21-23, San Francisco, USA.

[16] Thirumarimurugan M, Sivakumar V. M, Merly Xavier A, Prabhakaran D, Kannadasan T (2012) Preparation of Biodiesel from Sunflower Oil by Transesterification. International Journal of Bioscience, Biochemistry and Bioinformatics vol.2, pp. 441-444

[17] Hara M (2009) Environmentally benign production of biodiesel using heterogeneous catalysts. Chem. Sus. Chem,vol.2, pp. 129-135. doi:10.1002/cssc.200800222

[18] Sharma YC, Singh B, Upadhyay SN (2008) Advancements in development and characterization of biodiesel: A review. Fuel, vol.87, pp. 2355-2373. doi:10.1016/j.fuel.2008.01.014

[19] Mishra AK, Das D (2010) Investigation on Fe-doped ZnO nanostructures prepared by a chemical route, Materials Science and Engineering B, vol. 171, pp. 5-10. doi:10.1016/j.mseb.2010.03.045

[20] Wenlei Xie, Zhenqiang Yang, Hong Chun (2007) Catalytic Properties of Lithium-Doped ZnO Catalysts Used for Biodiesel Preparations. Ind. Eng. Chem. Res, vol. 46, pp. 7942-7949. doi:10.1021/ie070597s 


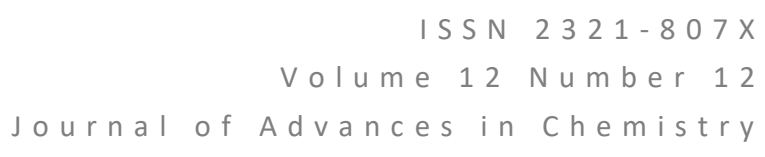

[21] Tamilmagan, Aruna Maheswari, Priya Bijesh, Andal Gopal (2015) Biodiesel production from waste cooking oil using green synthesized nanoFe ${ }_{2} \mathrm{O}_{3}$ and $\mathrm{CuO}$ impregnated nano $\mathrm{Fe}_{3} \mathrm{O}_{4}$. International Journal of ChemTech Research, vol.8, pp. 90-96.

[22] Yimer S, Sahu O (2014) Optimization of Biodiesel Production from Waste Cooking Oil. Sustainable Energy, vol.2, pp. 81-84. doi:10.12691/rse-2-3-1

[23] Alhassan FH, Yunus R, Rashid U, Sirat K, Lee Al H.V, Taufiq-Yap YH (2013) Production of biodiesel from mixed waste vegetable oils using Ferric hydrogen sulphate as an effective reusable heterogeneous solid acid catalyst. Applied Catalysis A: General, vol.456, pp. 182-187. doi:10.1016/j.apcata.2013.02.019

[24] Kumaran P, Mazlini N, Hussein I, Nazrain M, Khairul M (2011) Technical feasibility studies for Langkawi WCO (waste cooking oil) derived biodiesel. Energy, vol.36, pp. 1386-1393. doi:10.1016/j.energy.2011.02.002

[25] Hossain A.B.M.S, Boyce A.N (2009) Biodiesel production from waste sunflower cooking oil as an environmental recycling process and renewable energy. Bulgarian Journal of Agricultural Science, vol. 15(4), pp. 312-317.

[26] Meng X, Chen G, Wang Y (2008) Biodiesel production from waste cooking oil via alkali catalyst and its engine test. Fuel Process Technol, vol.89, pp. 851-857. doi:10.1016/j.fuproc.2008.02.006

[27] Zabeti M, Wan Daud W M A, Aroua M K (2009) Activity of solid catalysts for biodiesel production: A review.Fuel process Technol, vol.90, pp. 770-777. doi:10.1016/j.fuproc.2009.03.010

[28]Leung D.Y.C, Guo Y (2006) Transesterification of neat and used frying oil:Optimization for biodiesel production. Fuel Processing Technology, vol. 87, pp. 883-890. doi:10.1016/j.fuproc.2006.06.003

[29] Meher L.C, Vidya Sagar, Naik S.N (2006) Technical aspects of biodiesel production by transesterification - a review. Renew. Sust. Energy Rev. vol.10, pp. 248-268. doi:10.1016/j.rser.2004.09.002

[30]Gnanaprakasam A, Sivakumar V.M, Surendhar A, Thirumarimurugan M, Kannadasan T(2013)Recent Strategy of Biodiesel Production from Waste Cooking Oil and Process Influencing Parameters: A Review. Journal of Energy, vol.1-10. doi:10.1155/2013/926392

[31] Kambiz Tahvildari, Yasaman Naghavi Anaraki, Reza Fazaeli, Sogol Mirpanji, Elham Delrish (2015) The study of CaO and $\mathrm{MgO}$ heterogenic nano-catalyst coupling on transesterification reaction efficacy in the production of biodiesel from recycled cooking oil. Journal of Environmental Health Science \& Engineering, vol.13, pp. 73:1-9. doi: 10.1186/s40201015-0226-7

[32] Feng Guo, Zhen-Gang Peng, Jian-Ying Dai,Zhi-Long Xiu (2010) Calcined sodium silicate as solid base catalyst for biodiesel production.Fuel Processing Technology, vol.91, pp. 322-328. doi: 10.1016/j.fuproc.2009.11.003 